Www.jmscr.igmpublication.org

Index Copernicus Value: 79.54

ISSN (e)-2347-176x ISSN (p) 2455-0450

crossrefDOI: https://dx.doi.org/10.18535/jmscr/v7i2.30

Original Research Article

\title{
An epidemiological study of prevalence of anaemia and its correlates among adolescent girls in the rural area of Rohtas district, Bihar, India
}

\author{
Authors
Dr Seema Kumari ${ }^{1}$, Dr Dharmvir Ranjan Bharati ${ }^{2 *}$, Dr D K Yadava ${ }^{3}$, Dr Ajay Kumar ${ }^{4}$, Binish Inam ${ }^{5}$ \\ ${ }^{1}$ Department of Community Medicine, Narayan Medical College, Jamuhar, Sasaram, Bihar, India \\ ${ }^{2}$ Department of Community Medicine, Indira Gandhi institute of Medical sciences, Sheikhpura, Patna, \\ Bihar, India. \\ ${ }^{3}$ Department of Community Medicine, Narayan Medical College, Jamuhar, Sasaram,Bihar, India \\ ${ }^{4}$ Department of Pathology, MGM Medical College, Kishanganj, Bihar, India \\ ${ }^{5}$ Department of Community Medicine, Narayan Medical College, Jamuhar, Sasaram, Bihar, India \\ *Corresponding Author \\ Dr Dharmvir Ranjan Bharati \\ Additional Professor, Department of Community Medicine, Indira Gandhi institute of Medical sciences, \\ Sheikhpura, Patna 800014, Bihar, India \\ Email: drbharati1971@gmail.com, Contact No.7004796724
}

\begin{abstract}
Background: Adolescents girls constitute constitute about $20 \%$ of the population a vulnerable group as get traditionally married at an early age, they are exposed to a greater risk of reproductive morbidity and mortality.

Aims and Objectives: (1) To find out the prevalence of anaemia among adolescent girls. (2) To find its various risk factors among adolescent girls

Materials and Methods: A community based cross-sectional study was carried out in one village of Rural Health Training Centre, Nahauna, Department of Community Medicine, Narayna Medical College, Jamuhar, Sasaram, district Rohtas, Bihar during November- December 2018. Total 142 adolescent girls who are residing in the study area were included in the study.

Results: The prevalence of anaemia among adolescent girls was 59.2\%. Out of 84 anaemic girls, 62 $(73.8 \%)$ were mild anaemic, 18 (21.4\%) were moderate anaemic and 04 (4.8\%) were severely anaemic. Prevalence of anaemia was significantly higher in girls' of late adolescent period, of illiterate or primary educated mothers, undernourished, history of heavy menstrual flow and not taking iron folic acid tablets in last 6 months.

Conclusion: The overall prevalence of anaemia among adolescent girls was found to be 59.2\%. A significant association of anaemia with mother's educational status and under notion of adolescent girls suggests a need to develop strategies for intensive female nutrition education, anaemia prophylaxis has been given to all girls as well as improve the socio-economic status of the population through poverty alleviation programs to reduce the prevalence rate of anaemia among adolescent girls.

Keywords: Adolescent girls, Anaemia, under nutrition, menstrual bleeding, IFA tablets.
\end{abstract}




\section{Introduction}

Adolescents, between the ages of 10-19 years, ${ }^{1}$ constitute about $20 \%$ of the population in South-East Asian countries. Irrespective of severity, the anaemia prevalence among adolescent girls ranges between $17 \%$ (in Thailand) to $90 \%$ (in India) within the Region. ${ }^{2}$ The National Family Health Survey-3 (NFHS-3) data suggests that anemia among adolescent girls (15-19 years) is 56 percent. ${ }^{3}$ Anaemia is still one of India's major public health problems, despite of iron and folic acid supplementation by the Government of India through the National Nutritional Anaemia Prophylaxis Programme. ${ }^{4}$ Among adolescents, girls constitute a vulnerable group, particularly in because if such anemic adolescent girls get traditionally married at an early age, they are exposed to a greater risk of reproductive morbidity and mortality. The anemia in adolescent girls attributes to the high maternal mortality rate, the high incidence of low birth weight babies, high perinatal mortality in their further life. ${ }^{5}$ Deficient iron status or anaemia among adolescent girls is a major cause of growth retardation ${ }^{6}$, impaired physical and mental development, delayed menarche, morbidity, and future poor reproductive outcomes. Besides inadequate iron consumption, other major direct major causes of anaemia are high menstrual blood loss, malaria, and hookworm infestation. In addition to these direct causes, there are indirect socioeconomic factors such as illiteracy, poverty, and rural residence that affect anemia. ${ }^{4}$ It is therefore imperative to identify the burden of anaemia and the cause among adolescent girls for appropriate intervention. ${ }^{7}$ Therefore, this study was carried out to find prevalence of anaemia and its various risk factors among adolescent girls residing in rural area of Sasaram in Rohtas district of Bihar.

\section{Material and Method}

\section{Study design and setting:}

In the village Sahpur of population 1180 belongs to Rohtas district of Bihar, which comes under the field practice area of Rural Health Traning Centre,
Nahauna, Department of Community Medicine, Narayna Medical College, Jamuhar, Sasaram, district Rohtas, Bihar, a community based, cross sectional survey was conducted during NovemberDecember 2018.

\section{Sample size and sampling design:}

According to survey registers of Rural Health and Training Centre, the total number of adolescent girls in the age group of 10- 19 years was 205 in Sahpur village. It was decided to include all adolescent girls in the age group 10-19 years for the study. Out of all adolescent girls, 142 girls were included in the study as the rest of the girls were either absent in their houses or sick during data collection or girl's whose parents did not given consent or not willing for the haemoglobin $(\mathrm{Hb}) \%$ estimation were excluded from the study.

\section{Inclusion criteria}

All the adolescent girl aged 10 to 19 years from defined area willing to participate in the study and given written by adolescent girls and her mothers or father or guardian.

\section{Exclusion criteria}

Anyone not fulfilling inclusion criterion.

\section{Study questionnaire}

Data were collected from the study subject by the chief investigator by door to door visit at her house in a friendly atmosphere after obtaining the written consent from adolescent girls and her mothers or father or guardian. A pre-designed, pre-tested semi-structured questionnaire was used to collect the information from the participants. The questionnaire was pre-tested on ten students each from two schools selected purposively from other area out of five schools included in the study. Necessary modifications were made in the questionnaire before the start of study. Information regarding socio-demographic characteristics like age, Dietary habit, consumption of Iron Folic Acid (IFA) tablet, educational status mother, type of family and numbers of siblings, and personal history like 
history of worm infestation, excessive menstrual bleeding in the past 3 months and dietary history were collected. Relevant clinical examination including height, weight and haemoglobin percent estimation was done. WHO classification of anaemia and severity of anaemia was used in this study. All adolescent had haemoglobin concentration less than 12 grams per decilitre considered as anaemic. Among anemic, haemoglobin $(\mathrm{Hb})$ concentration between 11.0 $11.9 \mathrm{~g} / \mathrm{dl}$ were considered Mild anemia, $\mathrm{Hb}$ between 8.0-11.9 g/dl were considered Moderate anemia and $\mathrm{Hb}$ less than $8 \mathrm{~g} / \mathrm{dl}$ considered severe anaemia. $^{8}$

\section{Data collection}

Body weight was measured (to the nearest $0.5 \mathrm{~kg}$ ) with the subject standing motionless on the weighing scale with feet $15 \mathrm{~cm}$ apart, and weight equally distributed on each leg. It was measured by using standard electronic weighing machine and weight was recorded without any footwear. Height was measured (to the nearest $0.5 \mathrm{~cm}$ ) with the subject made to stand barefoot on a flat floor against the scale in an erect position against a vertical scale of portable stadiometer and with the head positioned so that the top of the external auditory meatus was in level with the inferior margin of the bony orbit. Body mass index (BMI) was calculated as weight in kilograms / (height in meter)2. Overweight and obesity was assessed by BMI for age. ${ }^{9}$ Student who had BMI for age $>85$ th and $<95^{\text {th }}$ percentile of reference population were classified as overweight. Students who had BMI for age $>95^{\text {th }}$ percentile of reference population were classified as obese.

Collection of blood samples: It was done under strict aseptic precaution. $2 \mathrm{ml}$ of venous blood was drawn by venepuncture from ante cubital vein and it was collected with ethylene diamine tetra-acetic acid. Haemoglobin was estimated by cyan methemoglobin method at the Rural Health and Training Centre.

\section{Statistical analysis}

Interpretation and analysis of the data were done using Epi-info 2018 v 7.2.2.6 Software (developed by Centers for Disease Control and Prevention (CDC) in Atlanta, Georgia, USA) and Chi-squire test was used for statistical significance. Odds ratio (OR) and 95 per cent confidence interval (95\% CI) was calculated for each categorical risk factor. $\mathrm{P}$ value of $<0.05$ was taken as significant.

\section{Results}

Our study showed, the prevalence of anaemia among adolescent girls was found to be 84 (59.2\%). Out of 84 anaemic girls, most of the girls (73.8\%) were suffering from a mild degree of anaemia, $18(21.4 \%)$ were suffering from a moderate degree of anaemia and only $4(4.8 \%)$ were found to be severely anaemic. (Table 1) Out of 142 adolescent girls, $67(47.2 \%)$ were in early adolescent group, $45(31.7 \%)$ were in middle adolescent group and $30(21.1 \%)$ belonged to late adolescent age group. $101(71.1 \%)$ mothers of adolescent girls have completed primary education or less and 41 (28.9\%) have studied up to secondary education or above. The present study findings showed 97 (68.3\%) families were nuclear type followed by $45(31.7 \%)$ were joint families. $113(79.6 \%)$ adolescent were had two or more siblings while $29(20.4 \%)$ had one or no sibling. Majority of the study subjects in the present study were vegetarian (66.9\%) as compared to only $33.1 \%$ were mix-veg. When girls were assessed for nutritional status by assessing body mass index (BMI), it was observed that $86(60.6 \%)$ of the girls were below the 5th percentile i.e. under weight and $56(39.4 \%)$ of the girls were in the normal range of BMI i.e. 5th to 85th percentile for girls and no one was overweight or obese. (Table 2)

Present study findings showed that proportion of anaemia was $73.3 \%$ amongst late adolescent age group the as compared to $62.2 \%$ in mid and $50.8 \%$ in early adolescent age group, difference between magnitude of anaemia amongst late adolescent was significantly more as compared to the early adolescent. Those adolescent girls whose mothers were educated primary or less found more anaemic compared to girls of highly educated 
mothers $(\mathrm{P}=0.0000)$. Adolescent girls who had taken IFA tablets within last 6 months had lesser prevalence of anaemia compared to those who had not taken the same, and this association was found statistically significant $(\mathrm{P}=0.0023)$. Also prevalence of anaemia was found more in girls with heavy menstrual flow $(\mathrm{P}=0.0073)$ and girls with under-nutrition i.e. $<5$ th percentile of BMI for girls $(\mathrm{P}=0.0001)$ compared to nutritionally normal adolescents. However history of worm infestation was weakly associated $(\mathrm{p}=0.040)$. Other personal characteristics like dietary habit, type of family, number of siblings did not show any significant association with the presence of anaemia (Table 2).

Table 1: Distribution of adolescent girls according to severity of anaemia $(n=142)$.

\begin{tabular}{|l|c|c|}
\hline Anaemia & $\mathbf{N}(\%)$ & $\mathbf{N}(\%)$ \\
\hline Absent & $58(40.8 \%)$ & \\
\hline & & \\
\hline Present $(\mathrm{Hb} \%<12 \mathrm{~g} / \mathrm{dl})$ & $84(59.2 \%)$ & $62(73.8 \%)$ \\
\hline & Mild $(11.0-11.9 \mathrm{~g} / \mathrm{dl})$ & $18(21.4)$ \\
\hline & Moderate $(8.0-11.9 \mathrm{~g} / \mathrm{dl})$ & $04(4.8 \%)$ \\
\hline
\end{tabular}

Table 2: Distribution of adolescent girls according to various demographic and personal factors associated with anaemia - univariate analysis.

\begin{tabular}{|c|c|c|c|c|c|}
\hline Variables & $\begin{array}{c}\text { Total (142) } \\
\text { N }(\%) \\
\end{array}$ & $\begin{array}{c}\text { Normal (58) } \\
\mathbf{N}(\%) \\
\end{array}$ & $\begin{array}{c}\text { Anaemic girls (84) } \\
\mathrm{N}(\%)\end{array}$ & Odds Ratio (95\% CI) & p-value \\
\hline \multicolumn{6}{|l|}{ 1. Age (Adolescent) } \\
\hline 10-14 (Early) & $67(47.2)$ & $33(49.2)$ & $34(50.8)$ & 1 & \\
\hline$>14-17$ (Middle) & $45(31.7)$ & $17(37.8)$ & $28(62.2)$ & $1.5968(0.7403-3.4519)$ & 0.2310 \\
\hline$>17-19$ (Late) & $30(21.1)$ & $8(26.7)$ & $22(73.3)$ & $2.6691(1.0423-6.8351)$ & $\mathbf{0 . 0 3 7 3}$ \\
\hline \multicolumn{6}{|l|}{ 2. Mother Education } \\
\hline Primary or less & $101(71.1)$ & $28(27.7)$ & $73(72.3)$ & $\begin{array}{c}7.1108(3.1418- \\
16.0921) \\
\end{array}$ & 0.0000 \\
\hline Secondary or more & $41(28.9)$ & $30(73.2)$ & $11(26.8)$ & 1 & \\
\hline \multicolumn{6}{|l|}{ 3. Type of Family } \\
\hline Joint & $45(31.7)$ & $14(31.1)$ & $31(68.9)$ & $1.8383(0.8709-3.8802)$ & 0.1079 \\
\hline Nuclear & $97(68.3)$ & $44(45.4)$ & $53(54.6)$ & 1 & \\
\hline \multicolumn{6}{|l|}{ 4. Number of sibling } \\
\hline$\geq 2$ & $113(79.6)$ & $43(38.1)$ & $70(61.9)$ & $1.7442(0.7671-3.9658)$ & 0.1815 \\
\hline 1 or nil & $29(20.4)$ & $15(51.7)$ & $14(48.3)$ & 1 & \\
\hline \multicolumn{6}{|l|}{ 5. Dietary habit } \\
\hline Vegetarian & $95(66.9)$ & $39(41.1)$ & $56(58.9)$ & $0.9744(0.4782-1.9852)$ & 0.9429 \\
\hline Mix-veg & $47(33.1)$ & $19(40.4)$ & $28(59.6)$ & 1 & \\
\hline \multicolumn{6}{|l|}{$\begin{array}{l}\text { 6. History of worm } \\
\text { infestation }\end{array}$} \\
\hline Present & $31(21.8)$ & $8(25.8)$ & $23(74.2)$ & $2.3566(0.9705-5.7222)$ & 0.0540 \\
\hline Absent & $111(78.2)$ & $50(45.1)$ & $61(54.9)$ & 1 & \\
\hline \multicolumn{6}{|l|}{ 7. Menstrual flow (125) } \\
\hline Heavy & $39(31.2)$ & $6(15.4)$ & $33(84.6)$ & 3.5962 (1.3614-9.4994) & 0.0073 \\
\hline Normal & $86(68.8)$ & $34(39.5)$ & $52(60.5)$ & 1 & \\
\hline \multicolumn{6}{|l|}{ 8. Nutritional status } \\
\hline Under nutrition & $86(60.6)$ & $24(27.9)$ & $62(72.1)$ & $3.9924(1.9552-8.1522)$ & 0.0001 \\
\hline Normal & $56(39.4)$ & $34(60.7)$ & $22(39.3)$ & 1 & \\
\hline \multicolumn{6}{|l|}{$\begin{array}{l}\text { 9. IFA tablet taken } \\
\text { within } 6 \text { months }\end{array}$} \\
\hline No & $117(82.4)$ & $41(35.0)$ & $76(65.0)$ & 3.9390 (1.5664-9.9058) & 0.0023 \\
\hline Yes & $25(17.6)$ & 17 & 8 & 1 & \\
\hline
\end{tabular}




\section{Discussion}

Anaemia is one of the major challenges India is still facing. During adolescence in girls, the nutrition and health needs are more because of the growth spurt and increase in physical activity as well as Initiation of menstruation in a girl in the adolescent period is an added burden and serves as a trigger to the already vulnerable adolescent girl to develop anaemia.

Present study findings showed the prevalence of anaemia among adolescent girls was found to be $84(59.2 \%) .^{5}$ and Jagannath Dabade Kuldeep et $\mathrm{al}^{10}$ reported $68.5 \%$ and $78.5 \%$ prevalence respectively from two different rural area of from Aurangabad. Baral $\mathrm{KP}^{11}$ reported $78.3 \%$. prevalence of iron deficiency anaemia among adolescent girls. Our results are also consistent with Dutt $\mathrm{R}$ et al ${ }^{12}(61 \%)$, Chandra Sekharet et al ${ }^{13}$ $(68.95 \%)$. Out of 84 anaemic girls, most of the girls $(73.8 \%)$ were suffering from a mild degree of anaemia, $18(21.4 \%)$ were suffering from a moderate degree of anaemia and $4(4.8 \%)$ were found to be severely anaemic. Kuril Bina $M$. etal ${ }^{5}$ reported similar trend. Jagannath Dabade Kuldeep et $\mathrm{al}^{10}$ reported $(75.8 \%)$ girls were suffering from a mild degree of anaemia and 31 (24.2\%) were suffering from a moderate degree of anaemia. No one was found to be severely anaemic.

In our study it was observed that magnitude of anaemia amongst late adolescent $73 \%$ was significantly more as compared to the early adolescent $50.8 \%$. Kuril Bina $M$. et $\mathrm{al}^{5}$ in his study observed that prevalence of anaemia was higher $(78.46 \%)$ in late adolescent girls than in early adolescent girls. Biradar $\mathrm{S}$ etal ${ }^{14}$ also observed that the prevalence of anaemia was high $(60 \%)$ in late adolescents (15-19 yrs.) as compared to $38.9 \%$ in the early adolescents (10-14 yrs.). Gupta $\mathrm{A}$ et $\mathrm{al}^{3}$ also found that the age of the adolescent girls shows a significant relation with the prevalence of anaemia. While results of studies done by Dutt $\mathrm{R}$ et $\mathrm{al}^{12}$ and Chaudhary SM et $\mathrm{al}^{15}$ reported no significant association of age of adolescent girls and anaemia.
In this study, significant association was found between the prevalence of anaemia and educational status of the mother, and it reflects better awareness among mothers with higher education. Similar association was founded by Jagannath Dabade Kuldeep et al reported $68.5 \%$ and $78.5 \%$ prevalence respectively from two different rural area of from Aurangabad and Chaudhary and Dhage ${ }^{15}$ in their study.

In our study, we found that the prevalence of anaemia was not significantly associated with Type of family, dietary habit and number of siblings to study participants. Similar observation reported by other researches, Kuril Bina M. et $\mathrm{al}^{5}$, Chaudhary SM et $\mathrm{al}^{15}$, Dutt $\mathrm{R}$ et $\mathrm{al}^{12}$ and Ramzi M et al. ${ }^{16}$ Type of family and number of siblings had not shown any significant association with anemia in adolescent girls was reported by Jagannath Dabade Kuldeep etal. ${ }^{10}$

In this study heavy menstrual flow, not consumed IFA tablets within last 6 months and girls with under-nutrition were was significantly associated with anaemia. However history of worm infestation was weakly associated. Similar observation reported by Kuril Bina M. et $\mathrm{al}^{5}$ and Jagannath Dabade Kuldeep etal. ${ }^{10}$

\section{Conclusion and Recommendations}

The overall prevalence of anaemia among adolescent girls was found to be $59.2 \%$.

A significant association of anaemia with mother's educational status suggests a need to develop strategies for intensive female education and to improve the socio-economic status of the population through poverty alleviation programs. Nutrition education and anaemia prophylaxis has been given to all girls to reduce the prevalence rate of anaemia among adolescent girls and on various health and health issues. Prevalence rate can be reduced by including iron rich foods and changing their dietary habits.

\section{Acknowledgment}

Author is thankful for help of multipurpose worker female, Social Worker of Rural Health 
Training Centre, Nahauna, Department of Community Medicine, Narayana Medical College, Jamuhar, Bihar, India, anganwadis, ASHA and grateful to adolescent girl respondents for their cooperation.

Financial support and sponsorship: Nil.

Conflicts of interest: There are no conflicts of interest.

\section{References}

1. UNICEF. State of the world's children. New York: United Nations Press, 2005.

2. Prevention of deficiency anaemia in adolescents, role of weekly iron and folic acid supplementation prevention of iron. http://apps.searo.who.int/PDS_DOCS/B47 70.pdf?ua=1

3. Gupta A, Ms.Anuradha, Dr.Rakesh Kumar, Dr.Virender Singh Salhotra Ms. Anshu Mohan DSR. Guidelines for Control of Iron Deficiency Anaemia. New Delhi; 2013 p.54.

4. Bharati Premananda, Shome Suparna, Chakrabarty Suman, Bharati Susmita, and Pal Manoranjan, Burden of anemia and its socioeconomic determinants among adolescent girls in India. Food and Nutrition Bulletin,2009, vol. 30, no. 3:217226.

5. Kuril Bina M, Lone Deepak K, Janbade Chetan, Ankushe R T, Gujarathi V V. Prevalence and risk factors of anaemia among adolescent girls in rural area Prevalence and risk factors of anaemia among adolescent girls in rural area. International Journal of Recent Trends in Science And Technology, ISSN 22772812 E-ISSN 2249-8109, Volume 14, Issue 3, 2015 pp 617-622.

6. Kaur TJ, Kochar GK, Agarwal T. Impact of nutrition education on nutrient adequacy of adolescent girls. Stud Home Community Sci 2007;1:51-5.
7. Ramachandran R, Majumdar A, Kar SS. Prevalence and risk factors of anaemia among adolescent girls residing in a rural community of Puducherry. Indian $\mathbf{J}$ Matern Child Health 2013;15:1-10.

8. Haemoglobin concentrations for the diagnosis of anaemia and assessment of severity.

https://www.who.int/vmnis/indicators/hae moglobin.pdf

9. Overview of the CDC growth charts. Available from URL: http://www.cdc.gov/nccdphp/dnpa/growth charts/training/modules/module2/text/page 1a.htm

10. Jagannath DK, Kuldeep DS, Narendra S Madhekar, Hrishikesh A Khadilkar, Vivek S Behere. Prevalence and Sociodemographic Factors Related to Anemia among Adolescent Girls in a Rural Area of Aurangabad District, Maharashtra. International Journal of Scientific Study | November 2014 | Vol 2 | Issue 8:19-23.

11. Baral KP, Onta SR. Prevalence of anemia amongst adolescents in Nepal: a community based study in ruraland urban areas of Morang District. Nepal Med. Coll. J. [Internet]. 2009 Sep; 11(3):179-82. Available from: http://www.ncbi.nlm.nih.gov/pubmed/203 34065.

12. Dutt R, Patil S, Joshi S, Mhatre R. Prevalence of anaemia among adolescent girls in rural area of Raigaddistrict, Maharashtra. 2009; 40(3):3-613.

13. Chandra Sekhar K, V NJ, Kumar KJK, Kumar DSS, Krishna CB, Tondare D. Prevalence of anaemia among adolescent girls in urban areas of Kadapa, A.P. Indian J. Public Heal. Res. Dev. Dr. R.K. Sharma; 2011; 2(1).

14. Biradar S, Biradar S. Prevalence of Anaemia among Adolescent Girls: A One Year Cross-Sectional Study. J. Clin. 2012 [cited 2013 Nov 23]; 6(3):372-7. 
15. Chaudhary SM, Dhage VR. A study of anemia among adolescent females in the urban area of Nagpur. Indian J. Community Med. 2008 Oct; 33(4):243-5.

16. Ramzi M, Haghpanah S, Malekmakan L, Cohan N, Baseri a, Alamdaria, et al. Anemia and iron deficiency in adolescent school girls in kavarurban area, southern Iran. Red Crescent Med. J. 2011. p. 12833. 